\title{
Diversity in medical education: data drought and socioeconomic barriers
}

\author{
Moneeza Walji MD MPH
}

B y 2031, about $30 \%$ of Canadians will be non-white. In cities such as Toronto and Vancouver, that proportion will reach $60 \% .^{1}$ As our cultural landscape changes, many medical education programs have embraced the need to create culturally and socially competent physicians. Ethnically and culturally diverse case studies have been added to the curriculum, and required teaching about Aboriginal and minority health issues has increased. Medical students are exposed to inner-city, rural and global health to develop social competency. However, training a truly socially and culturally competent physician is, arguably, best achieved by increasing diversity among trainees themselves.

Diversity is a broad concept that goes beyond visual differences. It encompasses variation in race, ethnicity, social and economic status, sexual orientation and physical ability. Training a diverse physician base enriches the health care system with a mix of individuals who may understand barriers to care more intimately and may be more likely to advocate effectively for their patients. Physicians from underrepresented visible minorities increase access to care directly because they are more likely to practise in medically underserved areas. ${ }^{2}$ Will our future medical profession appropriately reflect our increasingly diverse Canadian population? We do not really know the answer.

Until recently, Canada has paid little attention to documenting diversity among its medical students and physicians. The Association of Faculties of Medicine of Canada does not collect information on the ethnic, racial or socioeconomic background of medical students. The National Physician Survey began collecting these metrics on medical students and residents only in 2007. The survey is voluntary, and the response rate among medical students remains low (24\% in 2012). ${ }^{3}$ The Association of American Medical Colleges, in contrast, records the ethnic, racial and economic background of applicants and matriculants of medical schools across the United States.

The available Canadian data, incomplete as they are, show us that minority groups such as South, Southeast and East Asians are well represented in our medical schools. The number of medical students who identify as Aboriginal increased from $1.6 \%$ in 2007 to $4.4 \%$ in 2012 . This is welcome progress brought about in part through advocacy efforts as awareness of this missing group grew among physicians. However, only $2.9 \%$ of all medical students in 2012 reported identifying as African or Caribbean, which compares poorly with $4.2 \%$ of the general population nationally, and $5.8 \%$ in the province of Ontario, for example. ${ }^{4}$ Here, we could do more.

Data on socioeconomic status display a stark lack of diversity among medical students. In 2012, 56\% of Canadian households reported an income of less than $\$ 60000$ per year, yet only $23 \%$ of medical students came from families in that income category. ${ }^{3,5}$ Conversely, whereas only $23 \%$ of Canadian households earned more than $\$ 100000$ annually, 52\% of medical students came from families in that income group. ${ }^{3,5}$ These data on income help to highlight gaps in opportunity. All applicants to medical school face hurdles, but those from lower income groups may find their hurdles to be higher or more plentiful. Canadians do not have entirely equal access to education. Socioeconomic factors affect graduation from high school, access to higher education, preparing for and taking the Medical College Admissions Test, the medical school application process and paying the high cost of medical school tuition.

A lack of diverse representation among medical faculty means that mentorship for individuals from underrepresented groups may be difficult to find. True mentorship not only helps applicants through the arduous process of application and study, but also instills the confidence necessary to have high aspirations and achieve meaningful goals.

Canadians value racial colour-blindness. ${ }^{6}$ We celebrate our multicultural identity and our diversity, and perhaps we like to think that notable differences do not define who we choose as our friends or our future medical professionals. Our aversion to gathering data on physician diversity suggests that this sentiment runs deep. Yet our unwillingness to talk about race, ethnicity and social "class" does not mean the system treats everyone equally. Racial, ethnic and socioeconomic factors do influence who is admitted to medical school. Meaningful increases in the diversity of our physician workforce require interventions that target and address each of these barriers to ensure we are not making medicine a profession that is attainable to only a select few. We need to be rigorous about collecting data on diversity in the physician workforce and to develop programs to support those who are underrepresented.

See references, www.cmaj.ca/lookup/suppl/doi:10.1503/cmaj.141502/-/DC1

Competing interests: See www.cmaj.ca/site/misc/cmaj_staff.xhtml

Affiliation: Editorial Fellow, CMAJ.

Correspondence to: $C M A J$ editor, pubs@cmaj.ca

CMAJ 2015. DOI:10.1503/cmaj.141502 